\title{
Relationship of Body Mass Index with periodontal health status of green marble mine laborers in Kesariyaji, India
}

\section{Santhosh Kumar(a) \\ Rushabh J Dagli(a) \\ Chandrakant Dhanni ${ }^{(b)}$ \\ Prabu Duraiswamy ${ }^{(c)}$}

(a) BDS, Graduate student; (b)BDS, Lecturer; (c)MDS, Associate professor - Department of Preventive \& Community Dentistry, Darshan Dental College and Hospital, Udaipur, Rajasthan, India.
Corresponding author:

Santhosh Kumar Tadakamadla

Department of Preventive \& Community

Dentistry

Darshan Dental College and Hospital

Udaipur - Rajasthan - India

ZIP: 313001

E-mail: santosh_dentist@yahoo.com

Received for publication on May 09, 2008

Accepted for publication on Aug 03, 2009

\begin{abstract}
It is evident from literature that an increased body mass index (BMI) may be a potential risk factor for periodontitis. Association between BMI and periodontitis has been ascribed to unhealthy dietary patterns with insufficient micronutrients and excess sugar and fat content. The present study population has been plagued by unhealthy nutritional practices, hence the present study intended to assess the relation between BMI and periodontal status among green marble mine laborers of Kesariyaji, in the Udaipur district of Rajasthan, India. The study sample comprised of 513 subjects aged 18-54 years, drawn using the stratified cluster sampling procedure. BMI was calculated as the ratio of the subject's body weight (in $\mathrm{kg}$ ) to the square of their height (in meters). Periodontal status was recorded using the Community Periodontal Index (CPI). Binary multiple logistic regression analysis was executed to assess the relation between body mass index and periodontitis. The dependent variable for logistic regression analysis was categorized into control group (scores 0 - 2 of the CPI) and periodontitis group (scores 3 and 4 of the CPI). The overall prevalence of periodontal disease was $98.2 \%$. Caries status and mean number of teeth present deteriorated with the poor periodontal status. Subjects had an increased risk of periodontitis by $57 \%$ for each 1 $\mathrm{kg} / \mathrm{m}^{2}$ increase in the body mass index, which means that a higher body mass index could be a potential risk factor for periodontitis among the adults aged 18 to 54 years. In conclusion, evaluation of the body mass index could be used in periodontal risk assessment.
\end{abstract}

Descriptors: Periodontal diseases; Body mass index; Height by weight. 


\section{Introduction}

It is evident from the scientific literature that general health has a considerable impact on oral health and vice versa. Many mediators have been postulated for this relationship, namely infection, chronic inflammation, and genetic predisposition. ${ }^{1}$

Apart from these mediators, nutrition has been postulated as an alternative mediator. ${ }^{2}$ The body mass index has always been considered a simple method for analysis of the nutritional status. The normal value for this index ranges from $20-25 \mathrm{~kg} /$ sq.m. ${ }^{3}$ It is the value that better correlates with body fat.

Recently, studies have been conducted to assess the association of the body mass index and periodontitis. However, a study has even observed a significant association between caries frequency and the BMI, ${ }^{4}$ whereas another study found no correlation between dental decay in obese and non-obese children. $^{5}$

Sheiham et al. ${ }^{6}$ (2002) has stated that "The nature of the relationship between BMI and oral health is clearly rather complex. A low BMI is easily explainable on the basis of there being real functional difficulties that can prevent normal eating in some cases. On the other hand, the association of poor oral health with obesity is likely to be associated with the quality of the diet."

Though no definite mechanism of association between BMI and periodontitis is identified, it has been ascribed to unhealthy dietary patterns with insufficient micronutrients and excess sugar and fat content. These dietary patterns could thus pose a risk both for periodontal disease and obesity. ${ }^{7}$

The present study population has been plagued by unhealthy nutritional practices and is thus a good sample to study the association of body mass index and periodontal status.

The present study intended to assess the relation between body mass index (BMI) and periodontal status among green marble mine laborers of Kesariyaji, India.

\section{Material and Methods}

The final sample size comprised of 513 subjects aged 18 to 54 years. The study area, Kesariyaji is lo- cated in the Udaipur district of Rajasthan, India and it is divided into four geographical zones: Masoron Ki Obri, Rushabhdev, Khandiovri and Kagdar Bhatiya. Stratified cluster sampling was implemented to collect the representative population. ${ }^{8}$

The sampling procedures and exclusion criterion have been discussed in detail in a previous paper. ${ }^{9}$

The height of the participants was measured in centimeters, using a hard ruler installed vertically and secured with a stable base, while weight was assessed in kilograms using a mechanical scale. The scale used was certified by the Controller of Legal Metrology (Weights \& Measures), India.

The BMI was calculated as the ratio of the subject's body weight (in $\mathrm{kg}$ ) to the square of their height (in meters). Based on the WHO criteria, four categories were defined: underweight (BMI $<18.5 \mathrm{~kg}$ / $\mathrm{m}^{2}$ ), normal weight (BMI from 18.5 to $24.9 \mathrm{~kg} / \mathrm{m}^{2}$ ), overweight (BMI from 25 to $29.9 \mathrm{~kg} / \mathrm{m}^{2}$ ), and obese $\left(\mathrm{BMI}>30 \mathrm{~kg} / \mathrm{m}^{2}\right)$.

Oral examination was performed by a single examiner using a world health organization CPI periodontal probe. Periodontal status was recorded under five scores: score 0 (healthy), score 1 (bleeding), score 2 (calculus), score 3 (shallow periodontal pockets) and score 4 (deep periodontal pockets). ${ }^{8}$ Caries assessment was done using the Decayed, Missing and Filled Teeth index (DMFT), which was recorded following the WHO criteria ${ }^{10}$ for each subject.

Intra-examiner reliability for periodontal and DMFT assessment was analyzed by the weighted kappa statistic which was found to be $84.2 \%$ and $89.6 \%$ respectively. ${ }^{11}$

Ethical clearance for conducting the study was obtained from the Ethical Committee for Research, Darshan Dental College and Hospital.

The data was processed and analyzed using the statistical package for the social sciences (SPSS version 15.0). To facilitate the statistical analysis, the subjects were grouped into two categories based on CPI scores; individuals in the control group had a community periodontal index of $0-2$, whereas those in the periodontitis group had a community periodontal index of $3-4 .{ }^{12}$

The Mann-Whitney U test was used to analyze 
the significant differences between the two periodontal status categories in relation to age, BMI, DMFT and number of teeth present. Binary logistic regression analysis was performed to determine the relationship of BMI, age and DMFT. The dependent variable for the multiple logistic regression analysis was categorized into control group (scores 0 - 2 of the CPI) and periodontitis group (scores 3 and 4 of the CPI). All the independent variables were continuous and comprised of BMI, age and DMFT. Both adjusted and crude odds ratio were calculated for assessing the influence of various independent variables on the periodontal status with $95 \%$ confidence intervals. To analyze the adjusted odds ratio, the effect of each independent variable was assessed adjusting for all other variables in the model. A significance value of $\mathrm{p}<0.05$ was accepted as statistically significant.

\section{Results}

Table 1 presents the general profile of the study population. The youngest age group (18-24 years) contributed for one third of the sample size while there were fewer subjects who belonged to the oldest age group (45-54 years).

The overall prevalence of periodontal disease was 98.2\%. CPI scores 1 and 2 (bleeding and calculus) were more widespread among the study population whereas deep periodontal pockets were presented by $1.8 \%$ of the subjects.

None of the subjects were obese while more than half of the subjects $(67.6 \%)$ belonged to the 18.5 24.9 BMI group.

Mean subject characteristics with periodontal status are illustrated in Table 2 . There was a significant difference for age between the groups, with the mean age of the periodontitis group being approximately 3 years older than that of the control group.
A similar trend was noticed for the BMI with subjects belonging to the periodontits group presenting greater BMI. Caries status and mean number of teeth present deteriorated with the poor periodontal status.

Logistic regression analyses revealed that subjects had an increased risk of periodontitis by $57 \%$ for each $1-\mathrm{kg} / \mathrm{m}^{2}$ increase in body mass index (adjusted odds ratio, 1.57; 95\% confidence interval, 1.22-2.01). Moreover, though the risk of periodontis increased with the increase in age, its influence was not significant (Table 3).

\section{Discussion}

Previous data suggest that periodontal disease prevalence is greater among obese people, and studies have proposed that an increased body mass index

Table 1 - General profile of the study population.

\begin{tabular}{|c|c|}
\hline Characteristics & Percentage of subjects \\
\hline \multicolumn{2}{|c|}{ Age (years) } \\
\hline $18-24$ & 33.3 \\
\hline $25-34$ & 31.6 \\
\hline $35-44$ & 26.3 \\
\hline $45-54$ & 8.8 \\
\hline \multicolumn{2}{|c|}{ Periodontal status } \\
\hline CPI score 0 & 1.8 \\
\hline CPI score 1 & 45.6 \\
\hline CPI score 2 & 36.8 \\
\hline CPI score 3 & 14.0 \\
\hline CPI score 4 & 1.8 \\
\hline \multicolumn{2}{|c|}{ Body mass index $\left(\mathrm{kg} / \mathrm{m}^{2}\right)$} \\
\hline$<18.5$ (underweight) & 21.8 \\
\hline 18.5-24.9 (normal weight) & 67.6 \\
\hline 25.0-29.9 (overweight) & 10.5 \\
\hline$\geq 30.0$ (obese) & 0.0 \\
\hline
\end{tabular}

\begin{tabular}{|c|c|c|c|c|}
\hline \multirow{5}{*}{$\begin{array}{r}\text { Table } 2 \text { - } \\
\text { Characteristics of } \\
\text { subjects by periodontal } \\
\text { status. }\end{array}$} & Characteristics & CPI scores $0-2(n=432)$ & CPI scores 3-4 $(n=81)$ & $P$ \\
\hline & Age & $30.35 \pm 9.62$ & $33.78 \pm 7.54$ & 0.0001 \\
\hline & Body mass index $\left(\mathrm{kg} / \mathrm{m}^{2}\right)$ & $20.84 \pm 2.83$ & $24.23 \pm 3.44$ & 0.004 \\
\hline & DMFT & $2.44 \pm 2.83$ & $3.21 \pm 2.92$ & 0.002 \\
\hline & Number of teeth present & $28.47 \pm 0.34$ & $25.82 \pm 0.46$ & 0.001 \\
\hline
\end{tabular}

Mann Whitney U test. 
Table 3 - Crude and adjusted odds ratio and 95\% confidence interval (CI) of body mass index (BMI) and age as independent variables and presence of periodontal pockets as dependent variable (CPI $\geq 3=1, C P I \leq 2=0)$.

\begin{tabular}{c|c|c|c|c}
\hline & Crude Odds ratio (95\% Cl) & $P$ & Adjusted Odds ratio (95\% Cl) & $P$ value \\
\hline Age & $1.96(1.88-2.04)$ & 0.324 & $1.93(1.86-2.01)$ & 0.118 \\
\hline Body mass index & $1.52(1.19-1.94)$ & 0.001 & $1.57(1.22-2.01)$ & 0.0001 \\
\hline
\end{tabular}

may be a potential risk factor for periodontitis.

Past studies ${ }^{7,13,14}$ have included either young or old subjects and data from those studies on both the young and adult individuals had suggested that periodontal status deteriorates with BMI. The present study used a wide range of age, with the youngest individuals being 18 years of age and the oldest being 54 years of age.

However, the present study is not devoid of limitations, as the periodontal status was assessed using the Community periodontal index, which does not include all the teeth and does not measure attachment loss.

The overall prevalence of periodontal disease was $98.2 \%$ whereas this prevalence is $89.6 \%$ among the general population of India belonging to the 35 44 years age group. ${ }^{15}$ The higher prevalence of periodontal disease among the present study population can be attributed to a multitude of reasons like poor oral hygiene practices, poor living conditions and low access to dental health services. However, the widespread prevalence of bleeding and calculus is in accordance with previous studies. ${ }^{16-18}$

None of the subjects were obese while more than half of the subjects $(67.6 \%)$ belonged to the 18.5 24.9 BMI group. Moreover, the mean DMFT was greater in the periodontitis group when compared to the control group. This could be attributed to the influence of oral hygiene practices on both the diseases. Individuals who maintain good oral hygiene practices tend to be free from periodontal disease as well as decayed teeth.

It was observed that the subjects with higher BMI and age had an increased risk for periodontal disease.

The influence of age on periodontal disease is consistent with previous literature. Miyazaki et al. ${ }^{18}$ (1991) used the CPITN to assess the periodontal profiles of adults and found that the periodontal disease increased with the increase in age.

The present study population had an increased risk of periodontitis by $57 \%$ for each $1-\mathrm{kg} / \mathrm{m}^{2}$ increase in body mass index while the risk of periodontitis increased by $16 \%$ among young Japanese adults aged 18-24 years. ${ }^{13}$ This difference in risk might be due to the difference in age composition. Moreover, it is evident that the body mass index increases with age. ${ }^{19}$

Al-Zahrani et al. ${ }^{7}$ (2003) assessed the association of BMI and periodontal disease among adults aged 18-34 years and observed that the prevalence of periodontitis was $76 \%$ higher among obese individuals. Furthermore, Reeves et al. ${ }^{14}$ (2006) studied the association of body weight and waist size with chronic periodontitis among individuals aged 17-21 years and reported that weight significantly influenced the periodontal status.

Another study showed obese females to be 2.1 times more likely to have periodontitis than normal weight females. The risk increased to 3.4 times when the analysis was restricted to non-smokers. ${ }^{20}$

\section{Conclusions}

A higher body mass index could be a potential risk factor for periodontitis among adults aged 18 to 24 years. Thus, the evaluation of body mass index could be used in periodontal risk assessment. Longitudinal studies with a larger sample size are required to confirm the association of body mass index and periodontal disease.

\section{Acknowledgements}

The authors would like to thank Dr. Suhas Kulkarni, Head Professor, Department of Preventive and Community Dentistry, for his kind support and guidance for the study. 


\section{References}

1. Joshipura K, Ritchie C, Douglass C. Strength of evidence linking oral conditions and systemic disease. Compend Contin Educ Dent Suppl. 2000;(30):12-23.

2. Joshipura KJ, Douglass CW, Willett WC. Possible explanations for the tooth loss and cardiovascular relationship. Ann Periodontol. 1998 Jul;3(1):175-83.

3. Ganong WF. Review of medical physiology. $20^{\text {th }}$ ed. Stamford: McGraw Hill; 2001.

4. Willershausen B, Moschos D, Azrak B, Blettner M. Correlation between oral health and body mass index (BMI) in 2071 primary school pupils. Eur J Med Res. 2007 Jul 26;12(7):2959.

5. Moreira PV, Rosenblatt A, Severo AM. Prevalence of dental caries in obese and normal-weight Brazilian adolescents attending state and private schools. Community Dent Health. 2006 Dec;23(4):251-3.

6. Sheiham A, Steele JG, Marcenes W, Finch S, Walls AWG. The relationship between oral health status and Body Mass Index among older people: a national survey of older people in Great Britain. Br Dent J. 2002 Jun 29;192(12):703-6.

7. Al-Zahrani MS, Bissada NF, Borawskit EA. Obesity and periodontal disease in young, middle-aged, and older adults. J Periodontol. 2003 May;74(5):610-5.

8. World Health Organization. Community periodontal index. In Oral health surveys: basic methods. $4^{\text {th }}$ ed. Geneva: WHO; 1997.

9. Dagli RJ, Kumar S, Dhani C, Duraiswamy P, Kulkarni S. Dental health among green marble mine laborers, India. J Oral Health Comm Dent 2008;2(1):1-7.

10. World Health Organization. Oral health surveys, basic methods. $3^{\text {rd }}$ ed. Geneva: WHO; 1987.

11. Bulman JS, Osborn JF. Measuring diagnostic consistency. Br Dent J. 1989 May 20;166(10):377-81.
12. Ojima M, Hanioka T, Tanaka K, Inoshita E, Aoyama H. Relationship between smoking status and periodontal conditions: findings from national databases in Japan. J Periodontal Res. 2006 Dec;41(6):573-9.

13. Ekuni D, Yamamoto T, Koyama R, Tsuneishi M, Naito K, Tobe K. Relationship between body mass index and periodontitis in young Japanese adults. J Periodontal Res. 2008 Aug;43(4):417-21.

14. Reeves AF, Rees JM, Schiff M, Hujoel P. Total body weight and waist circumference associated with chronic periodontitis among adolescents in the United States. Arch Pediatr Adolesc Med. 2006 Sep;160(9):894-9.

15. Bali RK, Mathur VB, Talwar PP, Chanana HB. National oral health survey and fluoride mapping 2002-2003, Rajasthan. New Delhi: Dental Council of India; 2004.

16. Baelum V, Pisuithanakan S, Teanpaisan R, Pithpornchaiyakul W, Pongpaisal S, Papapanou PN et al. Periodontal conditions among adults in Southern Thailand. J Periodontal Res. 2003 Apr;38(2):156-63.

17. Wang HY, Petersen PE, Bian JY, Zhang BX. The second national survey of oral health status of children and adults in China. Int Dent J. 2002 Aug;52(4):283-90.

18. Miyazaki H, Pilot T, Leclercq MH, Barmes DE. Profiles of periodontal conditions in adults measured by CPITN. Int Dent J. 1991 Apr;41(2):74-80.

19. Hypponen E, Power C, Smith GD. Prenatal growth, BMI, and risk of type 2 diabetes by early midlife. Diabetes Care. 2003 Sep;26(9):2512-7.

20. Dalla Vechia CF, Susin C, Rösing CK, Oppermann RV, Albandar JM. Overweight and obesity as risk indicators for periodontitis in adults. J Periodontol. 2005 Oct;76(10):1721-8. 